\title{
POLICY, LICENSING, AND REGULATIONS
}

\section{LEARNING OBJECTIVES}

Upon the completion of Chapter 2, the reader will be able to:

- Explain the challenges in generically describing assisted living policy, licensing, and regulations.

- Cite examples of current changes to state regulation and policy.

- Describe state policy related to Medicaid reimbursement for assisted living.

- Describe policy and regulations related to assisted living labels, licensure, and philosophy.

- Recognize a variety of state regulatory models in assisted living.

- Understand the variability of policy and regulations related to assisted living communities.

- Describe federal statutes that impact assisted living.

\section{INTRODUCTION}

This chapter addresses key issues in assisted living policy, licensing, and regulations. Because states are primarily responsible for the monitoring and oversight of assisted living, this chapter provides a broad overview of the models and regulations used by individual states. An assisted living administrator is required to thoroughly understand the regulations and requirements specific to their individual state, which is beyond the scope of this book. This section addresses regulatory models and similarities and variations in policy and regulations across states. Key concepts typically covered by state regulations are discussed, including but not limited to assisted living philosophy, resident agreements and disclosure requirements, admission and retention criteria, and resident rights. Finally, a summary of federal laws that may pertain to the assisted living industry is included.

\section{The Challenge}

Although there are some similarities across states in the licensing, regulations, and policy relative to assisted living communities, these concepts are challenging to describe genericall for several reasons. Similar to the assisted living nomenclature and definitions, state regulations and policy are variable and continually changing. Assisted living is a broad and general licensing category in some states and a detailed model in others. Some states (as well as providers) utilize the term assisted living interchangeably with other terms, such as residential care, whereas others have 
different licensing categories based on size, services, and/or philosophy of care. For example, in California, the label "assisted living" is not used in the state regulations, but it is frequently used by clinicians. Furthermore, some states have additional licensure requirements that allow for higher levels of care to be provided, such as limited nursing care, specialized dementia care, and hospice care for the terminally ill.

The most comprehensive work in tracking state policy and regulation has been conducted by Dr. Robert Mollica and his colleagues. Paula Carder and her colleagues have continued to provide periodic updates to this work (Carder et al., 2015). Additional sources of information utilized for this chapter include the National Center for Assisted Living and recognized experts in the field. Furthermore, because there are no specific federal regulations for assisted living communities, the recommendations of the Assisted Living Workgroup from their report, Assuring Quality in Assisted Living: Guidelines for Federal and State Policy, State Regulations, and Operations, are included on important topics such as resident agreements, disclosure medication management, resident rights, and staff training requirements (Assisted Living Workgroup, 2003). The Assisted Living Workgroup was an initiative of approximately 50 national organizations, including clinicians, consumers, long-term care and healthcare professionals, and regulators that came together at the request of the U.S. Senate Special Committee on Aging to develop recommendations for federal guidelines for assisted living.

\section{STATE POLICY AND REGULATION}

State policy regarding regulations for assisted living communities continues to evolve. Every year some changes are made, so it is important for the assisted living administrator to be aware of current law, pending legislation, and newly developed or revised regulations. The National Center for Assisted Living (2019), in the report 2019 Assisted Living State Regulatory Review, provided summary information and examples of the current changes in state policy across the country. Some examples are:

More than half of states reported changes between June 2018 and June 2019 that will affect assisted living communities. Specifically, 27 states and the District of Columbia reported changes to a variety of requirements, either to the licensing requirements or to other regulations that also apply to assisted living providers (e.g., nursing scope of practice or life safety).

- Minnesota passed a bill finalizing comprehensive changes affecting assisted living providers. Effective in 2021 and subject to the rule-making process, the state will have two new levels of licensure: assisted living and assisted living with dementia care.

- States continue efforts to enhance protections for residents, which were the majority of changes. Specifically, the most common changes were to disclosure or notification requirements, efforts to prevent or address alleged abuse or neglect, staff training, emergency preparedness, and life safety.

- The most frequent change over the past year was an update to disclosure and notification requirements. Four states (Colorado, Minnesota, Oregon, and Virginia) and the District of Columbia passed laws requiring new types of notification either to the resident or to the state.

- Efforts to protect against elder abuse and neglect was another common change. Continuing last year's trend regarding state background checks, two states (Utah and West Virginia) reported updates for background checks of employees. 
- Both Minnesota and North Dakota passed legislation allowing a resident or the resident's representative to conduct electronic monitoring in the resident's room in specified circumstances.

- Twenty-three states reported no finalized legislative or regulatory changes between June 2018 and June 2019 affecting assisted living communities.

\section{Medicaid Reimbursement}

Although very limited in availability, many (42) states now have several options for using Medicaid to fund services in assisted living communities (Carder et al., 2015). As seen in Table 2.1, the majority of states currently utilize Home- and Community-Based Services waivers (also called 1915(c) waivers), others utilize state plans, and some utilize both. States' ability to expand the availability of home and community services to Medicaid is an ongoing challenge and often limited by resources.

\section{Labels}

The number of states utilizing the label assisted living has increased over time. Most states now have a licensing category or statute that uses the term assisted living. Some names used are assisted living, assisted living facility, assisted living residence, and assisted living community. Another common label is residential care, which includes terminology such as residential care facility, residential care home, or residential care facility for the elderly. In addition, some states continue to use traditional names such as board and care homes, homes for the aged, and personal care homes. Some states utilize more than one label for various types or levels of assisted living and residential care.

TABLE 2.1 STATES UTILIZING MEDICAID REIMBURSEMENT FOR ASSISTED LIVING

\begin{tabular}{|c|c|c|c|}
\hline HCBS WAIVER & & STATE PLAN & $\begin{array}{l}\text { HCBS WAIVERS AND } \\
\text { STATE PLAN }\end{array}$ \\
\hline $\begin{array}{l}\text { Alaska } \\
\text { Arizona } \\
\text { California } \\
\text { Colorado } \\
\text { Connecticut } \\
\text { Delaware } \\
\text { District of Columbia } \\
\text { Georgia } \\
\text { Hawaii } \\
\text { Illinois } \\
\text { Indiana } \\
\text { lowa } \\
\text { Kansas } \\
\text { Maryland } \\
\text { Mississippi } \\
\text { Minnesota } \\
\text { Montana }\end{array}$ & $\begin{array}{l}\text { Nebraska } \\
\text { Nevada } \\
\text { New Hampshire } \\
\text { New Jersey } \\
\text { New Mexico } \\
\text { Ohio } \\
\text { Oklahoma } \\
\text { Oregon } \\
\text { Rhode Island } \\
\text { South Dakota } \\
\text { Tennessee } \\
\text { Texas } \\
\text { Utah } \\
\text { Wyoming }\end{array}$ & $\begin{array}{l}\text { Michigan } \\
\text { Missouri } \\
\text { North Carolina } \\
\text { South Carolina }\end{array}$ & $\begin{array}{l}\text { Arkansas } \\
\text { Florida } \\
\text { Idaho } \\
\text { Maine } \\
\text { Massachusetts } \\
\text { New York } \\
\text { North Dakota } \\
\text { Vermont } \\
\text { Washington } \\
\text { Wisconsin }\end{array}$ \\
\hline
\end{tabular}

HCBS, home- and community-based services.

Source: From Carder, P., O'Keeffe, J., \& O'Keeffe, C. (2015). Compendium of residential care and assisted living regulations and policy: 2015 Edition. U.S. Department of Health and Human Services, Office of the Assistant Secretary for Planning and Evaluation, Office of Disability, Aging and Long-Term Care Policy and Research Triangle Institute. https:// aspe.hhs.gov/pdf-report/compendium-residential-care-and-assisted-living-regulations-and-policy-2015-edition 


\section{Licensure}

Although there are some federal laws that impact assisted living communities, the main public oversight is through the enforcement of state regulations. This generally occurs in the form of the initial licensure of communities, periodic license renewal surveys (inspection visits), and visits in response to consumer complaints or other administrative follow-up. All states have some kind of policy, regulations, or requirements for assisted living communities.

\section{Philosophy}

More than half of the states and the District of Columbia report that provisions regarding assisted living concepts such as privacy, autonomy, and decision-making are included in their assisted living regulations (Mollica et al., 2007). Overall, this philosophy represents a consumer-focused model where the delivery of care is centered on the resident. How the philosophy of assisted living is incorporated into state laws is highly variable. For example, regulations may state the importance of privacy and may require private unit residence while some states have mixed requirements, allowing bedrooms in some settings and individual apartments in others. Other states allow sharing (apartments or bedrooms) by resident choice. Two examples of how states incorporate the assisted living philosophy into their regulations come from Florida and Oregon (Mollica et al., 2007):

1. Florida's statute describes the purpose of assisted living as "to promote availability of appropriate services for elderly and disabled persons in the least restrictive and most home-like environment, to encourage the development of facilities which promote the dignity, privacy, and decision-making ability" of residents. Florida law also states that facilities should be operated and regulated as residential environments, not as medical or nursing facilities. Regulations require facilities to develop policies maximizing independence, dignity, choice, and decision-making.

2. Oregon, the first state to adopt a specific philosophy for assisted living, states that: assisted living is a program that promotes resident self-direction and participation in decisions that emphasize choice, dignity, privacy, individuality, independence, and home-like surroundings.

\section{Regulatory Models}

One way to consider state regulatory models is to consider the levels of care. Eric Carlson (2005) reviewed laws and regulations of all 50 states in his work with the National Senior Citizens Law Center. To understand the variation in state regulatory models, Carlson (2005) described two regulatory systems utilized by states:

\section{Single-level system}

In the single-level system, a state licensing agency licenses only one type of residential care/assisted living. In this model, any residential care/assisted living facility is licensed to accept or retain any resident, as long as the resident does not have a condition that disqualifies the resident from residential care/assisted living generally.

\section{Multilevel system}

In a multilevel system, residential care/assisted living facilities are licensed to care for residents only up to a particular care need. In this model, a resident typically may not be admitted or retained if they need a level of care that exceeds the specific level at which the facility is licensed. 
Many states recognize more than one level of care. For example, Florida allows communities to be licensed for standard assisted living services, limited nursing services, some mental health services, and extended congregate care. Arizona and Montana allow for multiple levels of care with each level allowing for a higher level of care to be delivered at the assisted living communities. Carlson (2005) made the important point that even states with "single level" systems (e.g., California) often allow for exceptions within state regulations for specific residents or communities.

\section{Unit Requirements}

The newer models of assisted living communities became popular with older persons in large part because of the privacy and ability to retain control over personal activities, such as bathing, dressing, eating, and sleeping. The older, more traditional homes offered shared rooms and bathrooms. Some stakeholders believe that private rooms must be made available to adhere to true assisted living philosophy, while others accept the use of shared rooms as a cost-effective alternative. Consequently, there are many types of occupancy styles in assisted living. This is controlled by both consumer demand and state regulations.

To describe the various models relative to facility size and unit types, Zimmerman and Sloane (2007) describe a three-part typology to understand the multiple classifications of assisted living facilities across various states:

1. Facilities with fewer than 16 beds,

2. Larger homes of the traditional board-and-care type,

3. New-model facilities with 16 beds or more-this new-model facility is described as (a) built in or after 1987 and (b) having two or more private-pay rates, at least $20 \%$ of residents who required assistance in transfer, at least $25 \%$ of residents who were incontinent, or a registered nurse or licensed practical nurse on duty at all times.

States set occupancy requirements in a variety of ways (Carder et al., 2015). Some states use the label assisted living for homes that only provide private rooms while other states allow for shared rooms to be offered. Some states have different licensing categories, allowing shared rooms in some settings and requiring private rooms in others.

\section{Resident Agreements/Contracts}

Dating back to 1999, the U.S. Government Accounting Office (GAO) reported that most assisted living communities provide information about services offered, but do not routinely provide information regarding discharge criteria, staff training and qualifications, services not available from the facility, grievance procedures, and medication policies. The majority of the $721 \mathrm{commu}-$ nities that responded to the GAO survey stated that they generally provide prospective residents with written information about many of their services and costs before they apply for admission. However, only about half indicated that they provide information on the circumstances under which the cost of services may change their policy on medication assistance, or their practice for monitoring residents' needs. Furthermore, less than half said they provide written information in advance about discharge criteria, staff training and qualifications, or services not covered or available from the facility. The report concluded that the provision of adequate information to prospective and current residents is a major issue that requires additional oversight. This issue has become a key topic in assisted living today, with consumer advocates expressing ongoing concern regarding the quality of resident agreements. 
To address these historic concerns, states now have more regulations and requirements relating to the resident agreement. According to Carder et al. (2015):

- Nearly all states require a residency agreement and describe the type of information that it must include. Some states also require clinicians to furnish a separate document to inform prospective residents about services and rates, typically called a Disclosure Statement.

- Most states specify that residency agreements must include information about basic services and fees, optional services if any, admission and discharge criteria, limits on the scope of services that may be provided, resident rights and responsibilities, and information for reporting grievances and complaints.

- Most states require the resident (or a representative, if there is one) to sign the contract, though the timing for doing so varies.

- Ten states require that the residency agreement include information about medication services and policies.

The Assisted Living Workgroup (2003) included the following recommendations regarding resident agreements/contracts within the resident rights component of their report, Assuring Quality in Assisted Living: Guidelines for Federal and State Policy, State Regulations, and Operations:

\section{Consistency in contracts and marketing}

All information conveyed by an assisted living residence to prospective residents (e.g., marketing materials, sales presentations, and tours) should be consistent with the contract.

2. Contracts and agreements: Consistency with applicable law

All contract provisions shall be consistent with applicable law. The parties may agree to modify the contract as long as all parties agree to the modification and signify their agreement. Such modification will be consistent with applicable law.

3. Contracts and agreements: Readability and pre-signing review

Contracts shall be written in simple language and be understandable. Prior to signinge, the prospective resident has the right to review a contract and/or have the contract reviewed by a third party. Prior to the execution of the contract, a representative of the assisted living residence shall offer to read and explain the contract and answer any questions.

\section{Contracts and agreements: Required elements}

Contracts/agreements should include at a minimum the following information:

a. The term of the contract,

b. A comprehensive description of the assisted living residence's billing and payment policies and procedures,

c. A comprehensive description of services provided for a basic fee,

d. A comprehensive description of the fee schedule for services provided on an á la carte basis or as part of a tiered pricing system that are not included in a basic fee,

e. The policy for changing the amount of fees,

f. The amount of advance notice the assisted living residence will give before the changing of fees (e.g., 30 days, 60 days); notices should be readable and understandable by the resident,

g. Whether the assisted living residence requires an entrance fee, security deposit, and/or other fee(s) at entry, the amount of those fees and/or deposits, the policies 
for whether or not fees and deposits are refundable, and procedures for refunding those fees and/or deposits,

h. A description of the circumstances under which residents may receive a refund of any prepaid amount such as monthly rent,

i. A description of the assisted living residence's policy during a resident's temporary absence,

j. The process for initial and subsequent assessments and the development of the service plan based on these assessments, including notification that the resident has the right to participate in the development of the service plan,

k. A description of all requirements for assessments or physical examinations, including the frequency and assignment of financial responsibility for such assessments and/or examinations,

1. An explanation of the use of third-party services (including all health services), how they may be arranged, accessed, and monitored (whether by the resident, family, or the assisted living residence), whether transportation is available if the services are not provided on-site, any restrictions on third-party services, and who is financially responsible for the third-party services and transportation costs,

m. A description of all circumstances and conditions under which the assisted living residence may require the resident to be involuntarily transferred, discharged, or evicted, an explanation of the resident's right to notice, the process by which a resident may appeal of the assisted living residence's decision, and a description of the relocation assistance (if available) offered by the assisted living residence,

n. A description of the assisted living residence's process for resolving complaints or disputes, including any appeal rights, and a list of the appropriate consumer/ regulatory agencies (if applicable; e.g., appropriate state/local long-term care ombudsman program, the state regulatory agency, the local legal services program, and other advocacy bodies/agencies),

o. A description of the procedures the resident or assisted living residence shall follow to terminate the agreement,

p. A list of residents' rights as detailed in the statute or regulations governing assisted living residences, incorporated by reference and attached.

\section{Contracts and agreements: Prohibition on waiver of right to sue}

The contract should not require the resident to waive the right to sue the assisted living residence under applicable law. The contract may disclose but not require options for alternative dispute resolution available to the resident or assisted living residence.

\section{Contracts and agreements: Third-party responsibility}

The contract shall disclose clearly that a signature by a third party (such as a "responsible party") does not indicate acceptance of any personal financial responsibility for fees, costs, or charges incurred by the resident, and does not make the third party a guarantor, unless the third party has signed a separate agreement indicating such. The separate agreement shall include, at a minimum, the following information:

a. Third party voluntarily agrees to be financially liable for paying the residents' expenses as agreed.

b. Third party has the right to have this agreement reviewed by an attorney or other person.

c. Third party has the right to revoke the separate agreement with 30 days' notice. 


\section{Preadmission Disclosures}

The Assisted Living Workgroup (2003) included the following recommendations regarding preadmission disclosure within the resident rights component of their report:

\section{Preadmission disclosure for specialized programs of care}

Assisted living residences that represent in any way that they provide special care programs for persons with Alzheimer's disease or other dementias, or any other specific health conditions, shall disclose how the program and its services are different from the basic services. At a minimum, the assisted living residence shall disclose the following information to each prospective resident prior to admission:

a. The assisted living residence's philosophy of the special care program,

b. The process and criteria for placement in, and transfer or discharge from, any specialized unit and/or the assisted living residence,

c. The process for assessing residents and establishing individualized service plans,

d. Additional services provided and the costs of those services relevant to the special care program,

e. Specialized (condition-specific) staff training and continuing education practices relevant to the special care program,

f. How the physical environment and design features are appropriate to support the functioning and safety of residents with the specific condition(s),

g. The frequency and types of activities offered to residents,

h. Options for family involvement and the availability of family support programs.

\section{Preadmission disclosure on advance directives}

Assisted living residences shall provide residents with information about their rights under state law to make decisions about medical care, including their right to accept or refuse health-related services, the right to formulate advance medical directives, such as a living will, a directive to physicians, or durable power of attorney for healthcare. The assisted living residence information should disclose its philosophy and policies about implementation of advance medical directives, including, but not limited to, implementation of Do Not Resuscitate orders (DNRs) and medical directives that require limitations on delivery of medical services, food, or hydration, and situations in which the assisted living residence is required to summon emergency medical services.

\section{Preadmission disclosure on end-of-life care}

Assisted living residences shall clearly disclose information to residents about applicable state laws and about the assisted living residence's philosophy and policies regarding delivery of end-of-life care, including delivery of hospice and palliative care services. Disclosure shall include the circumstances, if any, under which a resident with terminal illness or in the process of dying may be required to leave.

\section{Admission and Retention}

In general, states often utilize specific criteria that determine whether or not a person can be admitted to or retained in an assisted living community. Typically, these include the general condition of the resident, health-related conditions, functional conditions, physical function, cognitive function, behavioral problems, and health needs that may require the need for nursing care. A primary purpose of regulating admission and retention is to ensure that providers are able to meet the needs of the population they serve (Carder et al., 2015). The goal is to ensure that communities will be able to meet their residents' needs. 


\section{Resident Rights}

Regulations regarding resident rights are included in many states. Resident rights include such concepts as personal rights, disclosure of information regarding services and fees, and marketing practices. A further exploration of the significant challenges related to resident rights in assisted living communities is found in Chapter 23. The Assisted Living Workgroup (2003) included the following recommendations regarding resident rights in their report to the U.S. Senate Special Committee on Aging, Assuring Quality in Assisted Living: Guidelines for Federal and State Policy, State Regulations, and Operationsto the U.S. Senate Special Committee on Aging:

\section{Resident rights}

Within the boundaries set by law, residents have the right to:

a. Be shown consideration and respect;

b. Be treated with dignity;

c. Exercise autonomy;

d. Exercise civil and religious rights and liberties;

e. Be free from chemical and physical restraints;

f. Be free from physical, mental, fiduciary, sexual and verbal abuse, and neglect;

g. Have free reciprocal communication with and access to the long-term care Ombudsmen program;

h. Voice concerns and complaints to the assisted living residence orally and in writing without reprisal;

i. Review and obtain copies of their own records that the assisted living residence maintains;

j. Receive and send mail promptly and unopened;

k. Private unrestricted communication with others;

1. Privacy for phone calls and access to a phone;

m. Privacy for couples and for visitors;

n. Privacy in treatment and caring for personal needs;

o. Manage their own financial affairs;

p. Confidentiality concerning financial, medical, and personal affairs;

q. Guide the development and implementation of their service plans;

r. Participate in and appeal the discharge (move-out) planning process;

s. Involve family members in making decisions about services;

t. Arrange for third-party services at their own expense;

u. Accept or refuse services;

v. Choose their own physicians, dentists, pharmacists, and other health professionals;

w. Choose to execute advance directives;

x. Exercise choice about end of life care;

y. Participate or refuse to participate in social, spiritual, or community activities;

z. Arise and retire at times of their own choosing;

aa. Form and participate in resident councils;

ab. Furnish their own rooms, and use and retain personal clothing and possessions; 
ac. Exercise choice and lifestyle as long as it does not interfere with other residents' rights;

ad. Unrestricted contact with visitors and others as long as that does not infringe on other residents' rights;

ae. Have the rights that one would enjoy in one's own home, such as coming and going;

af. Residents' family members have the right to form and participate in family councils.

\section{Provider responsibilities}

The provider will:

a. Promote an environment of civility, good manners, and mutual consideration by requiring staff, and encouraging residents, to speak to one another in a respectful manner.

b. Provide all services for the resident or the resident's family that have been contracted for by the resident and the provider, as well as those services that are required by law.

c. Obtain accurate information from residents that is sufficient to make an informed decision regarding admission and the services to be provided.

d. Maintain an environment free of illegal weapons and drugs.

e. Obtain notification from residents of any third party services they are receiving, and to establish reasonable policies and procedures related to third-party services.

f. Report information regarding resident welfare to state agencies or other authorities as required by law.

g. Establish reasonable house rules in coordination with the resident council.

h. Involve staff and other providers in the development of resident service plans.

i. Maintain an environment that is free from physical, mental, fiduciary, sexual and verbal abuse, and neglect;

j. $\quad$ Require that providers of third-party services ensure that they and their employees have passed criminal background checks, are free from communicable diseases, and are qualified to perform the duties they are hired to perform.

\section{Services}

Services offereded in assisted living communities vary both by state admission and retention criteria, and by individual assisted living providers. Typically services that may be offered by assisted living communities include:

1. Twenty-four-hour care and supervision,

2. Oversight of personal and supportive services (assistance with activities of daily living and instrumental activities of daily living),

3. Health-related services (e.g., medication management services, hospice care),

4. Social services,

5. Recreational activities,

6. Meals and snacks,

7. Housekeeping and laundry,

8. Transportation. 
Many states now seek to allow communities to facilitate aging-in-place and to offer consumers a full range of long-term care options. However, in some cases, most states specify the range of allowable services and a minimum that must be provided, but do not require communities to provide the full range of allowable services. There are varying opinions on what services assisted living communities should be expected to provide. Some believe that assisted living should remain a social model, and communities should not be expected to provide services to persons with medically complex conditions or high levels of disabilities. On the other hand, some believe that assisted living communities should provide additional services to residents as care needs increase in an effort to minimize the need to relocate to a skilled nursing facility or nursing home.

\section{Training Requirements}

State regulations generally specify initial training requirements for assisted living administrators, as well as direct-care staff. However, some states stipulate general requirements, and others include specific topics, such as the number of hours required (see Chapter 5 for more information on direct-care staff training requirements).

\section{Administrator Requirements}

Administrator requirements also vary by state. Each state requires assisted living settings to employ a manager, director, or an administrator who is responsible for daily operations, including staffing, oversight, and complying with regulatory requirements (Carder et al., 2015). Generally, the administrator is expected to be employed full-time, but states may permit smaller settings with a licensed resident capacity under a specified number to employ a part-time administrator. Initial and ongoing training requirements for administrators are typically required.

\section{Direct Staff Requirements}

Assisted living communities employ direct-care workers to provide personal care and related daily services to residents. States use a variety of terms to describe these staff, including personal care assistant, attendant, and caregiver (Carder et al., 2015). Most often, these direct-care staff are unlicensed, though states may require training and/or certification, as seen in Chapter 5.

Carlson (2005) makes the important notation that direct-care standards for assisted living communities are far less stringent than those that apply to nursing home staff members, where under the terms of the federal Nursing Home Reform Law, direct-care staff must complete at least 75 hours of initial training under the supervision of a registered nurse with a minimum of 2 years' experience and at least 1 year of nursing experience in long-term care.

\section{Dementia Care}

States continue to adopt more regulations with regard to residents with dementia in assisted living (Carder et al., 2015). Two examples of the various additional requirements for communities serving dementia residents include:

\section{Disclosure}

Most states require that facilities disclose their dementia care-specific services. These facilities are required to describe in writing how they are different from other facilities. This may include philosophy of care, admission/discharge criteria, the process for arranging a discharge, services covered and the cost of care, and special activities that are available. 


\section{Staffing and training}

Most states now have requirements for dementia training and staffing for facilities serving people with Alzheimer's disease and other dementias, which may include additional training hours or staffing ratios.

\section{Medication Administration}

Medication management and administration is a key issue for assisted living communities that offers many challenges. In their report, Assisted Living: Quality of Care and Consumer Protection Issues, the U.S. General Accounting Office (1999, p. 3) found "not providing residents with appropriate medications and not storing medications properly" to be a common problem in assisted living facilities. Regulators have also cited medication administration and assistance with self-medication as a major concern (Mollica et al., 2007).

There is much variability in how states address medication issues within their regulations in assisted living communities. However, several states now report that they are paying closer attention to medication issues, including the tracking of medication problems as the acuity level of residents served increases. Some states allow for trained aides to administer medications, while others allow only trained aides to administer medications or to assist with self-administration of medications. Some states require communities to have a consulting pharmacist, and several states require licensed nurses to review medication records on a regular basis. Some states are now requiring additional training for direct-care staff who administer or assist with self-administration of medications (e.g., California).

The Assisted Living Workgroup (2003, p. 170) included the following recommendation with regards to medication management in their report, Assuring Quality in Assisted Living: Guidelines

for Federal and State Policy, State Regulations, and Operations, to the U.S. Senate Special Committee on Aging:

The assisted living residence will have and implement policies and procedures for the safe and effective distribution, storage, access, security, and use of medications, related equipment, and services of the residence by trained and supervised staff.

Policies and procedures of the residence should address the following issues:

1. Medication orders, including telephone orders;

2. Pharmacy services;

3. Medication packaging;

4. Medication ordering and receipt;

5. Medication storage;

6. Disposal of medications and medication-related equipment;

7. Medication self-administration by the resident;

8. Medication reminders by the residence;

9. Medication administration by the residence;

10. Medication administration-specific procedures;

11. Documentation of medication administration;

12. Medication error detection and reporting;

13. Quality-improvement system, including medication error prevention and reduction; 
14. Medication monitoring and reporting of adverse drug effects to the prescriber;

15. Review of medications (e.g., duplicate drug therapy, drug interactions, monitoring for adverse drug interactions);

16. Storage and accountability of controlled drugs;

17. Training, qualifications, and supervision of staff involved in medication management.

\section{Quality-Assurance Efforts}

As the interest in assisted living has increased, so have concerns about quality of care and safety that can be provided to those residents who require special care, staffing, and physical and social environments. These concerns have been described in media reports throughout the country and in a 1999 report from the U.S. General Accounting Office (U.S. GAO; 1999). In 2004, the U.S. GAO issued another report, Assisted Living: Examples of State Efforts to Implement Consumer Protections, which describes the quality-assurance initiatives in Florida, Georgia, Massachusetts, Texas, and Washington.

Quality-assurance strategies by states described in the U.S. GAO report (2004) include:

1. Provide technical assistance and follow-up.

2. Act within 10 days on complaints.

3. Have clear lines of communication and definition of duties for survey staff.

4. Develop clear enforcement procedures that are well understood by state staff meeting with providers to discuss issues.

5. Provide training.

6. Conduct follow-up visits.

7. Maintain a consumer perspective that focuses on improving care, not just punishing past failures.

In addition, states described a number of initiatives to improve quality:

1. Provide training for providers.

2. Implement new training requirements for medication aides.

3. Revise the survey process.

4. Develop a more formalized consultation program.

5. Provide more technical assistance.

6. Conduct forums for providers to discuss quality issues.

7. Implement quality-assurance and quality-of-care initiatives.

Furthermore, additional strategies focused on conducting regulatory reviews to bring facilities up to national standards and to tighten standards for assessment, training, and level of care:

1. Work with providers to develop minimal standards for assessments, service plans, negotiated risk agreements, and disclosure requirements.

2. Add disclosure requirements for dementia care providers.

3. Increase staff training requirements.

4. Establish specific staffing requirements for special care units.

5. Increase requirements for a comprehensive resident assessment. 
Quality assurance and quality improvement continue to be key issues addessed by researchers, educators, industry professionals, and advocacy groups.

\section{FEDERAL STATUTES THAT IMPACT ASSISTED LIVING}

Although states are primarily responsible for the licensing and oversight of assisted living communities, federal statues also impact the operations of assisted living. Some examples of federal statutes that are important for the assisted living administrator to have knowledge of are offered by the Assisted Living Federation of America (2008):

\section{Americans With Disabilities Act}

The Americans With Disabilities Act (ADA) affects assisted living operators in two primary ways: first, as employers under Title I of that law; and second, as "public accommodations" under Title III of that law. Title I of the ADA covers all employers with 15 or more employees, although religious organizations may require all employees, including those with disabilities, to conform to their religious tenets. The principal obligation of employers under Title I of the ADA is to provide "reasonable accommodations" to employees with disabilities, which are defined as physical or mental impairments that substantially limit "major life activities"—-such as walking, breathing, and working-in order to allow them to perform the "essential functions" of a job. In addition, under Title I of the ADA, assisted living employers must refrain from making adverse decisions based on an individual's having a record of a physical or mental impairment, as well as from erroneously regarding an individual as disabled and treating him or her differently on that basis. Finally, the ADA prohibits employers from inquiring whether an applicant has a medical condition or disability prior to extending a conditional offer of employment. Alcoholism is a protected disability under the ADA, although current drug users (as opposed to the rehabilitated) are not covered under the Act, and the Act does not affect the ability of assisted living employers to test employees for drug use.

Title III of the ADA prohibits discrimination on the basis of disability by "commercial facilities" and "places of public accommodation' — such as "social service center establishments" and offices of "service establishments," regardless of size. Title III's prohibitions, however, do not apply to "religious organizations or entities controlled by religious organizations."

Under Title III of the ADA, "commercial facilities" are specifically defined to exclude residential facilities and facilities otherwise covered by or exempted from the requirements of the Fair Housing Act of 1968 as amended by the Fair Housing Amendments Act (FHAA) of 1988. Because the term $d$ welling" under the FHAA has been interpreted broadly, the coverage of assisted living facilities as "commercial facilities" under Title III of the ADA may be correspondingly narrow. However, as certain physically public parts of assisted living facilities, such as lobbies, hallways, sales and management offices, and parking lots, may separately qualify as "places of public accommodation" under Title III of the ADA, assisted living operators can expect the coverage of Title III of the ADA and the FHAA to overlap with respect to such areas. In any event, under either law, assisted living operators will generally be required to make those architectural modifications to facilities that do not constitute "undue hardships."

Moreover, to the extent an assisted living operator offers social services such as dining, counseling, and transportation to its residents, the public areas of an entire facility may independently be deemed a covered "place of public accommodation." As such, if a resident or guest meets the definition of "disabled" under the ADA, the resident will be entitled to reasonable accommodations 
that will allow the resident to access the facility and its services on a nondiscriminatory basis. Assisted living operations must ensure that their delivery of services does not result in any of the types of discrimination prohibited under Title III of the ADA. This generally will mean making reasonable accommodations to ensure that facilities and programs give the disabled equal opportunities to participate and benefit in the most appropriate integrated setting.

\section{Civil Rights Act of 1991}

The Civil Rights Act of 1991 consisted primarily of amendments to Title VII of the Civil Rights Act of 1964, which, like the ADA, covers assisted living operators employing 15 or more employees. It also affects the prohibition on intentional racial discrimination contained in the Reconstruction Civil Rights Act of 1866 (42 U.S.C. Sec. 1981), which covers assisted living operators regardless of the number of workers they employ.

Prior to the Civil Rights Act of 1991, Title VII of the Civil Rights Act of 1964 had been designed primarily to promote informal resolution of employment discrimination claims, and remedies were generally limited to declaratory judgments, injunctions, orders of reinstatements and/or backpay, and attorney's fees. The most dramatic change caused by the 1991 Act was the replacement of this system with a tort-like compensation scheme for intentional employment discrimination, including compensatory damages for emotional pain and suffering, punitive damages, and jury trials. Though it expanded the range of remedies available under Title VII, Congress also capped damages, however, at levels rising in three increments from $\$ 50,000$ to $\$ 100,000$, $\$ 200,000$, and $\$ 300,000$, for employers with up to $100,200,500$, and over employees, respectively. These caps notwithstanding, the 1991 Act still significantly raised the financial stakes and risks for assisted living operators litigating federal employment discrimination claims.

In addition, the 1991 Act specifically overruled several Supreme Court decisions that had narrowed the scope of the Reconstruction Civil Rights Act and Title VII. In particular, Congress reversed a 1989 Supreme Court decision that had limited the reach of the Reconstruction Civil Rights Act, and expanded the kinds of acts prohibited by that law to encompass intentional discrimination in virtually any aspect of the employment relationship. Second, Congress adopted the broad interpretation of "adverse impact" discrimination announced by the Supreme Court in a landmark 1971 case_Griggs v. Duke Power Co.—-thereby legislatively reversing another 1989 Supreme Court decision that briefly appeared to make it more difficult for plaintiffs to prevail in challenges to employment practices with disproportionate negative effects on classes of employees protected under Title VII. Finally, the 1991 Act also helped plaintiffs by partially reversing another 1989 decision of the Supreme Court_Price Waterhouse v. Hopkins-and newly allowing plaintiffs to "prevail" and receive declaratory judgments, injunctions, and attorney's fees even if an employer could establish that a decision adverse to an employee would have been made for legitimate reasons, any actual discriminatory motivation notwithstanding.

\section{Rehabilitation Act of 1973}

Section 504 of the Rehabilitation Act of 1973 applies to assisted living operators who receive federal financial assistance, and Section 503 of that Act applies to the rare operator who contracts with the federal government for more than $\$ 10,000$ in personal property or "nonpersonal" services annually. Generally speaking, if a facility directly or indirectly receives Medicaid funds, it will likely be deemed the "recipient" of federal financial "assistance."

If an assisted living operator is covered by Section 504, the operator will effectively have no more obligations than they already had under Titles I and III of the ADA. Thus, for all practical 
purposes, unless the operator is exempt from the ADA for some reason, Section 504 of the Rehabilitation Act will not impact its operation. If an assisted living operator also becomes covered under Section 503 of the Rehabilitation Act, however, wholly apart from any obligations the operator may have under Titles I or III of the ADA, they will also have an obligation to take affirmative action to employ the disabled.

\section{Family and Medical Leave Act}

The Family and Medical Leave Act (FMLA) requires assisted living operators with 50 or more employees to provide up to 12 weeks of unpaid leave for family and medical reasons to employees who have worked for them for at least 12 months and a total of 1,250 hours during the previous 12 -month period. Employers must maintain employees' preexisting group health insurance benefits while they are on FMLA leave, and must restore employees to the same or equivalent positions when their leave ends.

Employees can take FMLA leave for the birth of a child; adoption of a child; placement of a foster child; to care for a spouse, child, or parent with a "serious health condition"; or to care for a minor child who is unable to care for himself or herself due to a physical or mental disability as defined under the ADA. The statute also provides for leave for employees with "serious health conditions," defined as an "illness, injury, impairment or physical or mental condition that results in: (1) an overnight inpatient stay at a hospital, hospice, or residential medical care facility; (2) absence from work or other regular daily activities and continuing treatment for more than 3 days; or (3) continuing treatment for a chronic or long-term condition that if not treated would incapacitate the family member for more than 3 days" (The Family and Medical Leave Act of 1993, as amended).

An employee may take FMLA leave on a continuous or intermittent basis if medically necessary-such as when the employee or the employee's family member has an episodic illness. Though the law requires the employee give the employer 30 days' notice of needed FMLA leave when possible, fundamentally, the employee must simply make a reasonable attempt to schedule leave so as to minimize the disruption of the employer's operation. Moreover, employers may choose to designate paid leave as concurrent FMLA leave when taken by an employee qualifying for FMLA leave.

\section{Fair Housing Amendments Act}

The Fair Housing Amendments Act of 1988 altered Title VIII of the Fair Housing Act of 1968 in two main ways: First, it expanded the prohibitions contained in the Fair Housing Act to include discrimination in the sale or rental of "dwellings" on the basis of disability; and second, it enhanced the procedural enforcement options available for private litigants, as well as the Department of Housing and Urban Development (or its designated equivalent state or local agency, such as the City of Dallas), as they pursue relief under the Fair Housing Act.

Many of the residents of assisted living facilities qualify as "disabled" within the meaning of FHAA. Thus, the expansion of the Fair Housing Act to cover the disabled is having a complex effect on the assisted living industry. For example, on the one hand, the FHAA has put a new arrow in the quiver of assisted living operators faced with state and local regulations - uch as zoning restrictions - that can interfere with or prevent the construction of new (or expansion of operation of existing) facilities. On the other hand, however, the FHAA may result in new architectural burdens with respect to interior residential facilities, and may also create new potential liability for operators attempting to comply with state regulations that govern, for example, the placement of patients in assisted living (as opposed to long-term care) facilities. 
The changes in the enforcement procedures contained in the FHAA also significantly increase the financial risk faced by assisted living operators sued under the Fair Housing Act. In particular, in addition to lengthening the period of time during which complaints of discrimination can be brought, in stark contrast with the prior $\$ 1,000$ cap on punitive damages under the former law, the FHAA newly allows plaintiffs to recover unlimited punitive damages, and increases the ability of plaintiffs to recover attorney's fees in suits brought under the Fair Housing Act. Finally, the FHAA significantly enhances the ability of the federal government or its state or local agents to enforce the provisions of the Fair Housing Act in administrative proceedings and to recover fines for violations.

\section{Fair Labor Standards Act}

The Fair Labor Standards Act of 1938 (FLSA) is the primary federal law setting the minimum wage, overtime pay, equal pay, record keeping, and child labor standards for employers in the assisted living industry. An assisted living employer will qualify as an "enterprise" covered under the FLSA - and its non-exempt employees will be covered-if it has a gross annual sales volume of $\$ 500,000$ or more, and two or more of its employees "handle," "sell," or "work on" goods or materials that have been "moved in or produced for commerce by any person." Depending on the precise nature of the services they provide, however, some assisted living operators may qualify for special exemptions from certain of the FLSA's requirements. These include, for example, exemptions related to individuals employed to provide companionship to the aged, "live-in" domestics, and workers residing on-site at their workplace.

As of July 24, 2009, the federal minimum wage is $\$ 7.25$ per hour. Employers with unionized employees may not negotiate agreements that waive employees' statutory rights under the FLSA. Thus, collective bargaining agreements may only contain provisions that are more beneficial to employees than what such employees would otherwise receive under the FLSA.

Many of the questions and complexities that arise under the FLSA derive from the rules governing what constitutes compensable "hours worked" under that law, and employer errors in interpreting these rules may be particularly significant because (especially where full-time employees are concerned) they can result in unpaid overtime liability. Waiting time, on-call time, breaks, sleep time, meal periods, training, and travel time are all governed by detailed rules requiring separate analyses based on the facts and circumstances of employment.

In addition, with certain limitations, the FLSA allows assisted living employers to institute certain "alternative" work schedules. For example, under 29 U.S.C. Sec. 270(j), employers "engaged in the operation of . . . establishment $[\mathrm{s}]$... primary engaged in the care of the . . . aged" can adopt a so-called " $8-80$ " payroll system whereby employees are scheduled to work 80 hours on a 14-day basis rather than 40 hours on a 7 -day basis.

\section{Occupational Safety and Health Act}

The Occupational Safety and Health Act of 1970 (OSHA) sets a national minimum standard for workplace safety. Section 18 of OSHA encourages states to develop and operate their own job safety and health programs, and OSHA approves and monitors state plans and provides up to $50 \%$ of an approved plan's operating costs. Some states, however, including Texas, do not maintain their own plans, and enforcement and the applicable statutes and regulations in such states are federal.

Employers of assisted living facilities have two general duties under OSHA: First, to furnish employees with employment (and a place of employment) that is free from recognized hazards 
that are likely to cause death or serious physical harm; and second, to comply with the detailed occupational safety and health standards promulgated under OSHA. Moreover, assisted living employers with 11 or more employees during the previous calendar year must keep records of occupational injuries and illness in the form of an OHSA Log 200.

OSHA compliance officers are authorized to inspect and investigate (at reasonable times and in a reasonable manner) places of employment for compliance with OSHA regulations, and are empowered to obtain injunctions, issue citations, and assess penalties for noncompliance through administrative proceedings.

\section{CONCLUSIONS}

This chapter provides the reader with an overview of state policy, licensing, and regulations for the assisted living industry. It is quite apparent that the states vary tremendously in regard to the licensing and monitoring of assisted living facilities. Although federal regulations do not currently exist, the reader is offered national guidelines and recommendations stemming from the work of prominent national organizations. Examples of federal statutes that impact assisted living facilities are described. This chapter illustrates the need for today's assisted living administrators to be well informed with regard to individual state laws and regulations and to remain updated as requirements are commonly changed and frequently modified.

\section{REFERENCES}

Assisted Living Federation of America. (2008). Federal statutes that impact assisted living. http://www.alfa .org/i4a/pages/index.cfm?pageid=3516

Assisted Living Workgroup. (2003). Assuring quality in assisted living: Guidelines for federal and state policy, state regulations, and operations. U.S. Government Printing Office. https://www.huduser.gov/portal/ publications/Assuring-Quality-in-Assisted-Living-Guidelines.html

Carder, P., O'Keeffe, J., \& O'Keeffe, C. (2015). Compendium of residential care and assisted living regulations and policy: 2015 edition. U.S. Department of Health and Human Services, Office of the Assistant Secretary for Planning and Evaluation, Office of Disability, Aging and Long-Term Care Policy and Research Triangle Institute. https://aspe.hhs.gov/pdf-report/compendium-residential-care-and-assisted-livingregulations-and-policy-2015-edition

Carlson, E. (2005). Critical issues in assisted living: Who's in, who's out and who's providing the care. National Senior Citizen's Law Center.

Mollica, R., Sims-Kastelein, K., \& O'Keeffe, J. (2007). Residential care and assisted living compendium, 2007. U.S. Department of Health and Human Services, Office of the Assistant Secretary for Planning and Evaluation, Office of Disability, Aging and Long-Term Care Policy and Research Triangle Institute. https://aspe.hhs.gov/system/files/pdf/75316/07alcom.pdf

National Center for Assisted Living. (2019). 2019 Assisted living state regulatory review. National Center for Assisted Living. https://www.ahcancal.org/ncal/advocacy/regs/Documents/2019_reg_review.pdf

U.S. General Accounting Office. (1999). Assisted living: Quality of care and consumer protection issues (GAO/ T-HEHS-99-111).

U.S. General Accounting Office. (2004). Assisted living: Examples of state efforts to implement consumer protections (GAO-04-684). https://www.gao.gov/assets/250/242237.pdf

Zimmerman, S., \& Sloane, P. (2007). Definitions and classification of assisted living. The Gerontologist, 47, 33-39. 